\title{
Types of Bariatric Surgery and Fat Reduction by Ultrasound Evaluation
}

\author{
Tomoyuki Kawada $^{1}$
}

Published online: 13 June 2015

(C) Springer Science+Business Media New York 2015

To the editor:

I read with great interest the article by Mizrahi et al. [1] that the authors compared visceral fat (VF) and subcutaneous fat (SCF) reduction measured by ultrasonography (US) after three types of bariatric surgery in 39 obese patients in a 1year follow-up study. The authors concluded that laparoscopic sleeve gastrectomy and laparoscopic Roux-En-Y gastric bypass showed better preferential and overall VF reduction than laparoscopic adjustable gastric bandin by US. I have some queries on their study outcome.

First, there is a report that the combination of body mass index (BMI) and waist circumference (WC) has a power predicting VF and cardio-metabolic risk [2]. Mizrahi et al. made an emphasis on the advantage of VF reduction by bariatric surgery, and data on WC reduction would be informative for mutual comparison among VF, SCF, and WC.

Secondly, the authors adopted a univariate analysis, partly because of the limitation in the number of samples. I previously mentioned critical view on advantage of bariatric surgery for patients with type 2 diabetes mellitus [3], with special emphasis on study design, ethnic difference, and present history of metabolic disease. In addition, sex and age seem to be important factors for fat reduction. To confirm the advantage of specific bariatric surgery, randomized-controlled trial seems indispensable.

Tomoyuki Kawada

kawada@nms.ac.jp

1 Department of Hygiene and Public Health, Nippon Medical School, 1-1-5 Sendagi, Bunkyo-Ku, Tokyo 113-8602, Japan

Finally, measures of VF and SCF by US should be handled with caution. US is a simple technique to measure visceral adipose tissue (VAT) [4, 5], but inter-individual difference of US measures exists [6]. Anyway, advantage of VAT reduction by bariatric surgery should be determined by adjusting several confounding variables for their analysis.

Disclosure Statement The author has no financial support.

Conflicts of Interest The author has no conflict of interest.

Compliance with Ethical Standards This article does not contain any studies with human participants or animals performed by any of the authors.

Informed Consent Informed consent does not apply to this article.

\section{References}

1. Mizrahi I, Beglaibter N, Simanovsky N, et al. Ultrasound evaluation of visceral and subcutaneous fat reduction in morbidly obese subjects undergoing laparoscopic gastric banding, sleeve gastrectomy, and Roux-en-Y Gastric Bypass: a prospective comparison study. Obes Surg. 2015;25(6):959-66.

2. Nazare JA, Smith J, Borel AL, et al. Usefulness of measuring both body mass index and waist circumference for the estimation of visceral adiposity and related cardiometabolic risk profile (from the INSPIRE ME IAA study). Am J Cardiol. 2015;115(3):307-15.

3. Kawada T. Advantage of bariatric surgery for patients with type 2 diabetes mellitus. J Hepatol. 2014;61(5):1188.

4. Armellini F, Zamboni M, Robbi R, et al. Total and intra-abdominal fat measurements by ultrasound and computerized tomography. Int J Obes Relat Metab Disord. 1993;17(4):209-14.

5. van der Kooy K, Seidell JC. Techniques for the measurement of visceral fat: a practical guide. Int J Obes Relat Metab Disord. 1993;17(4):187-96.

6. Tornaghi G, Raiteri R, Pozzato C, et al. Anthropometric or ultrasonic measurements in assessment of visceral fat? A comparative study. Int J Obes Relat Metab Disord. 1994;18(11):771-5. 